Reply

SIR,-We thank Drs Kochlar, Rajwanshi, and Mehta for their interest in our paper, and we look forward to reading their results when published. They correctly point out that since our paper was accepted Lange et al have published the results of a similar technique, although with a poor yield of readable samples. We believe our method of gentle movement of the needle tip in the specimen is helpful in increasing the amount of sample obtained, and may account for the difference in results.

We are also grateful to the writers for drawing our attention to abstracts of other work in this field which do not appear in Index Medicus as no full paper has apparently been published. Clearly several workers have found endoscopic needle aspiration cytology of the stomach to be practicable. We hope our evidence of its value in the diagnosis of gastric malignancy will encourage others to adopt the technique.

C J H INGOLDBY R I HALL M K MASON

Department of Surgery, Level 8, Room 8.20, Clinical Sciences Bldg, St James's University Hospital, Leeds LS9 7TF

\section{Staffing and administration of endoscopy}

SIR,-Y Your occasional report, 'Results of a questionnaire concerning the staffing and administration of endoscopy in England and Wales' highlights many inadequacies in the provision of endoscopy services in England and Wales. In particular I was concerned to read of the ongoing deficiencies in training for those working in endoscopy units and the apparent unwillingness of anyone in the NHS to pick up this responsibility and run with it.

My company as the major suppliers of endoscopes to the NHS has not neglected its responsibility in this area and is running training courses regularly which have now accommodated an aggregate of over 3000 nurses and technicians over 14 years. In addition, it has supported, with financial and practical aid, the only regular advanced endoscopy course for nurses. The importance to the NHS of these courses has been two-fold: better understanding of the instrumentation has both cut the cost of repairs (very considerably) and thereby helped in providing uninterrupted services for patients.

Your readers will be interested to compare the reported attendance at the ENB course with the current booking position for our primary course 'Care and maintenance' which is $85 \%$ fully booked three weeks after announcement, and has a waiting list for a suitable place of over 1500 potential delegates.

The procurement Directorate of the DHSS is encouraging more aggressive purchasing on value for money grounds, but in practice this rarely seems to take into account such 'invisibles' as user training. If the NHS wants such services then it must either be prepared to pay for them or to make the necessary very substantial investment in providing the courses that, as our waiting lists suggest, are in demand.

A H REDDIHOUGH

Managing Director,

KeyMed (Medical and Industrial Equipment) Ltd, KeyMed House,

Stock Road,

Southend-on-Sea,

Essex SS2 5QH.

Addendum to letter on p. 553 entitled 'Small intestinal adenocarcinoma. . . .' The authors wish to add the following: Jones and Marshall's paper prompted a further report by Kingston (Letter, Gut $1988 ; 29: 134$ ) of a periampullary tumour in a patient with neurofibromatosis. We have kindly been allowed to study this tumour which again proves to be a somatostatin-rich glandular carcinoid.

\section{Books}

Inflammatory bowel disease: a personal view by Henry D. Janowitz, M.D. (Pp. 179; illustrated; \$42.95.) Chicago, USA, Field, Rich, 1985.

This is not a textbook but a sharing of unrivalled experience. Dr Janowitz began work at the Mount Sinai Hospital, New York, in 1939 and has devoted much of his professional life to inflammatory bowel disease ever since. He has worked with Crohn, Ginzberg, and Oppenheimer and many other distinguished colleagues, he has lead a distinguished research team himself, and he has experience of countless patients. The recurring problems of the patients with inflammatory bowel disease are dealt with practically and sympathetically. The rare occurrences in a long busy career, such as massive haematuria caused by bladder involvement in Crohn's disease, add particular interest. A well produced set of small intestinal radiographs sharpen our knowledge of differential diagnosis, and remind us that Crohn's disease has many mimics.

Medical practice in a sophisticated tertiary referral 
centre in New York has much to teach us in this country where patients are becoming more knowledgeable and anxious to discuss the arguments for and against different policies of treatment. Dr Janowitz's advice is always balanced and based not only on his own experience but on a wide knowledge of the literature. There is a striking identity of view between his opinions and current practice in Britain; it is heartening that over one third of the references in his selected bibliography come from this country and almost half from Europe.

It is refreshing to read a short well produced book in which the author is free to express his own opinions. Anyone who has to advise and treat patients with inflammatory bowel disease, whether as a physician or surgeon, cannot fail to learn something new from this book and, more important, gain an insight, into the warm, sympathetic, and yet incisive approach of a great clinician.

J E LENNARD-JONES

Water movement through lipid bilayers, pores, and plasma membranes By A Finkelstein. (Pp. 228; $£ 38$ 45.) Chichester: John Wiley, 1987.

This short book is a monograph in the Wiley Interscience Distinguished Lecture series of the Society of General Physiologists. It concentrates primarily on the theoretical basis for water movement across membranes and there is very little discussion of transport across whole epithelia. The monograph is divided into three sections, the first concentrating on a theoretical framework for the examination of movement of water across membranes and deals with such topics as osmotic transport, unstirred layers, single file transport, and porous membranes. Part 2 describes experimental data obtained from artificial lipid bilayers and includes the effects of the polyene antibiotics such as Nystatin and Amphotericin B which have the ability to render membranes much more permeable to anions and Gramicidin A, an antibiotic which renders membranes permeable to cations. These activities are probably responsible for their antibacterial and antifungal activity but in the context of membrane transport they provide useful tools for studies on ion and water permeability. The final section deals with data on permeability derived from biological membranes and includes a short section on epithelial transport but concentrates primarily on the toad urinary bladder and on the red cell membrane.

The book is written in a lively and interesting manner. The large amount of theoretical discussion is made easily understandable and although not exhaustive and not intended specifically for gastro- enterologists, the monograph is a useful introduction for researchers entering the field of gastrointestinal epithelial transport. Much is currently being written about intestinal 'permeability' and this book also helps clarify what permeability is and what it is not.

LESLIE TURNBERG

Clinics in gastroenterology 14:2 Edited by $\mathrm{T}$ A S Buist. (Pp. 192; illustrated; £13.50.) E Sussex: W B Saunders, 1986.

This book is an excellent collection of short essays by distinguished authors and covers vascular procedures in gastrointestinal radiology, interventional radiology of the biliary tract, and percutaneous biopsy and abscess drainage.

All of the chapters are well written but one or two of them are disappointingly short and fail to give the depth of coverage needed to be of practical value. The chapter on percutaneous abscess drainage is particularly short considering the authors' extensive experience in this field.

There are a few omissions which would have been of interest to the general reader. Pancreatic interventional procedures receive almost no coverage. The role of percutaneous pancreatography, catheter drainage of pseudocysts and management of pancreatic abscesses merit inclusion. Percutaneous cholecystostomy and gastrostomy are important new techniques which escape mention.

On the whole this is a well written and up to date review of interventional radiology in gastroenterology and is a useful contribution to the literature.

W R LEES

Practical laparoscopy by G Berci and A Cuschieri. (Pp. 182; illustrated; £19.50.) London: Baillière Tindall, 1986.

Despite the popularity of laparoscopy in continental Europe it has never really caught on with British gastroenterologists. This is a pity because the technique has so much to offer especially in the management of liver disease. Practical laparoscopy the British and American authors state is an introductory manual which emphasises the technique and practical use of laparoscopy. In this they have succeeded and their book will undoubtedly help to popularise laparoscopy. The book is compact, easy to read, and well illustrated. Its contents include how to set up the instruments, comprehensive accounts of numerous laparoscopic procedures, documentation, and even emergency gynaecological laparoscopy. Most importantly it abounds with practical advice 